\title{
Characterization of alkanes, hopanes and polycyclic aromatic hydrocarbons (PAHS) in tar-bals collected from the East Coast of Peninsular Malaysia.
}

\begin{abstract}
The East Coast of Peninsular Malaysia faces the South China Sea and is vulnerable to oil pollution because of intense petroleum production activities in the area. The South China Sea is also a favored route for supertankers carrying crude oil to the Far East. Consequently, oil spills can occur, causing pollution and contamination in the surrounding areas. Residual oil spills stranded on coastal beaches usually end up as tar-balls. Elucidating the sources of tarballs using a molecular marker approach is essential in assessing environmental impacts and perhaps settling legal liabilities for affected parties. This study utilizes a multimodal molecular marker approach through the use of diagnostic ratios of alkanes, hopanes, and polycyclic aromatic hydrocarbons (PAHs) to determine the source, distribution and weathering of tar-balls. Hopane ratios (e.g., C29/C30, and $\sum \mathrm{C} 31-\mathrm{C} 35 / \mathrm{C} 30$ ratios) were used to identify the sources of tar-balls. The weathering effects were distinguished by using alkanes, namely the unresolved complex mixture (UCM) and low molecular weight/high molecular weight $(\mathrm{L} / \mathrm{H})$ ratios. Similarly, PAHs were also used for the determination of weathering processes undergone by the tar-balls. This multimodal molecular marker gave a very strong indication of the sources of tar-balls in this study. For example, 16 out of 17 samples originated from South East Asian Crude Oil (SEACO) with one sample from Merang, Terengganu originating from North Sea Oil (Troll). The TRME-2 sample may have come from a supertanker's ballast water discharge. The second possibility is that the tar-ball may have been transported via oceanographic currents. All 'weathered' sample characterizations were based on the presence of UCM and other ratios. The multimodal molecular marker approach applied in this study has enabled us to partially understand the transport behavior of tar-balls in the marine environment and has revealed insights into the weathering process of tar-balls.
\end{abstract}

Keyword: Tar-balls; Oil spill; Molecular marker; Hopanes; PAHs. 